ISSN 1981-416X

Licenciado sob uma Licença Creative Commons

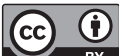

\title{
Base nacional comum curricular e Ensino Médio: reflexões à luz da conjuntura contemporânea
}

\author{
Unified national basic curriculum and high school: \\ reflections in the light of contemporary conjuncture
}

Ana Lara Casagrande, Katia Morosov Alonso, Danilo Garcia da Silva*

Universidade Federal de Mato Grosso (UFMT), Cuiabá, MT, Brasil

\section{Resumo}

Neste texto objetivamos refletir sobre a educação dos jovens do Ensino Médio, na perspectiva do estabelecimento da Base Nacional Comum Curricular (BNCC). Realiza-se uma pesquisa de abordagem qualitativa, desenvolvida a partir da análise documental, cuja fonte central é o Ministério da Educação, ao mesmo tempo em que se promovem discussões (desenvolvidas junto ao procedimento de análise bibliográfica) acerca do currículo e dualidade educacional, para contextualizar o impacto de uma base comum em um país de dimensões continentais e pluralidades culturais como o Brasil. Constata-se que a política educacional está ligada a programas de governo, sobretudo quando se aborda currículo: revelador de dinâmicas de identidade e poder. Garantir conteúdos mínimos, ao mesmo tempo em que traz uma noção de universalização dos conhecimentos e aprendizagens iniciais a serem adquiridas, pode gerar uma padronização reducionista, isto é, o risco é o de desenhar-se um descompasso

*ALC: Doutora em Educação, e-mail: analaracg@gmail.com KMA: Doutora em Educação, e-mail: katia.ufmt@gmail.com DGS: Doutor em Educação, e-mail: danilogsilvas@gmail.com 
entre a formação integral para todos, conceito complexo por ser minimalista na essência, e o trabalho limitante de diretrizes confundidas com um currículo único. Discutimos, ainda, a BNCC em relação aos programas de formação para o magistério e a importância da temática permear esse contexto. Há um reconhecido problema de disparidade quanto ao acesso ao conhecimento, assim, a qualidade educacional não será materializada fora das discussões sobre currículo, política, formação docente e sistema econômico.

Palavras-chave: BNCC. Ensino Médio. Currículo. Política educacional.

\section{Abstract}

In this text, we have the objective of reflecting on the education of the young people of High School, with a view to the establishment of the National Curricular Common Base (NCCB). A qualitative research is developed, based on the documentary analysis, whose central source is the Ministry of Education, while promoting discussions (developed with the bibliographic analysis procedure) on the curriculum and the educational duality, to contextualize the impact of a common base in a country with continental dimensions and cultural pluralities such as Brazil. It is noted that educational policy is linked to government programs, especially when addressing curriculum: revealing dynamics of identity and power. Ensuring minimum contents, while at the same time bringing a notion of universalization of the knowledge and initial learning to be acquired, can generate a reductionist standardization, that is, the risk is to draw a gap between integral formation for all, concept complex because it is minimalist in essence, and the limiting work of guidelines confused with a basic curriculum. We also discussed the NCCB in relation to the formation programs for the teaching profession and the importance of the theme to permeate this context. The problem of disparity in access to knowledge is recognized, so quality in education will not be reached outside of discussions about curriculum, policy, teacher training, and the economic system.

Keywords: NCCB. High school. Curriculum. Educational politics. 


\section{Resumen}

En este texto pretendemos reflexionar sobre la educación de los jóvenes de la Enseñanza Secundaria, en la perspectiva del establecimiento de la Base Nacional Común Curricular (BNCC). Se realiza una investigación de abordaje cualitativo, desarrollada a partir del análisis documental, cuya fuente central es el Ministerio de Educación, al mismo tiempo que se promueven discusiones (desarrolladas junto al procedimiento de análisis bibliográfico) sobre el currículo y la dualidad educativa, para contextualizar el impacto de una base común en un país de dimensiones continentales y pluralidades culturales como Brasil. Se constata que la política educativa está ligada a programas de gobierno, sobre todo cuando se aborda currículum: revelador de dinámicas de identidad y poder. Garantizar contenidos mínimos, al mismo tiempo que trae una noción de universalización de los conocimientos y aprendizajes iniciales a ser adquiridos, puede generar una estandarización reduccionista, es decir, el riesgo es el de dibujar un descompaso entre la formación integral para todos, concepto complejo por ser minimalista en esencia, y el trabajo limitante de directrices confundidas con un currículo único. Discutimos, además, la BNCC en relación a los programas de formación para el magisterio y la importancia de la temática permear ese contexto. Hay un reconocido problema de disparidad en cuanto al acceso al conocimiento, así, la calidad educativa no será materializada fuera de las discusiones sobre currículo, política, formación docente y sistema económico.

Palabras-clave: BNCC. Enseñanza Secundaria. Currículum. Política educativa.

\section{Introdução}

A Base Nacional Comum Curricular (BNCC) estabelecida para o Ensino Médio se materializa em meio à proposta de reformulação para a etapa via Medida Provisória $n^{0} 746$, de 22 de setembro de 2016, que se converteu na Lei n 13.415, de 16 de fevereiro de 2017 (BRASIL, 2017a). A reforma ser aprovada via Medida Provisória chama a atenção, mas Oliveira (2005, p. 763) afirmou há alguns anos, ao discutir regulação das políticas 
públicas, que Programas educacionais, em âmbito nacional, impostos "sem a mediação dos órgãos intermediários do sistema, têm sido uma constante nas reformas implementadas nas últimas duas décadas". Peroni (2003, p. 90), por sua vez, considera que "o fato do Ex ecutivo atuar por meio de medidas provisórias têm, como base teórica, a Escola de Virgínia, conhecida como Public Choice, um dos pilares teóricos do neoliberalismo".

Essa Lei que institui a Política de Fomento à Implementação de Escolas de Ensino Médio em Tempo Integral altera o artigo 36 da Lei de Diretrizes e Bases da Educação Nacional (LDB), Lei n 9.394, de 20 de dezembro de 1996, estabelecendo, com relação ao currículo do Ensino Médio, que "será composto pela Base Nacional Comum Curricular e por itinerários formativos, que deverão ser organizados por meio da oferta de diferentes arranjos curriculares".

$\mathrm{Na}$ apresentação do documento inerente à BNCC, o então ministro da Educação à época, Mendonça Filho, afirmou que tal base curricular está prevista nas principais legislações brasileiras, que tratam da educação, como a Constituição de 1988, a Lei de Diretrizes e Bases da Educação Nacional, de 1996, e o Plano Nacional de Educação, de 2014, sendo que o documento expressaria o "compromisso do Estado Brasileiro com a promoção de uma educação integral e desenvolvimento pleno dos estudantes".

Efetivamente, desdea Constituição Federal do Brasil, estabelece-se a necessidade de fixar-se "conteúdos mínimos para o ensino fundamental, de maneira a assegurar formação básica comum e respeito aos valores culturais e artísticos, nacionais e regionais" (BRASIL, 1988, art. 210). A LDB, por sua vez, afirma que a União deverá estabelecer competências e diretrizes para a educação básica, em colaboração com os demais entes federados responsáveis pelos sistemas de ensino, "que nortearão os currículos e seus conteúdos mínimos, de modo a assegurar formação básica comum" (BRASIL, 1996, art. 9, inciso IV).

Especificamente com relação ao Ensino Médio, o Plano Nacional de Educação mais recente (PNE - 2014/2024), promulgado via Lei $\mathrm{n}^{\mathrm{o}}$ $13.005 / 2014$, estabelece a meta de universalizar o atendimento escolar 
para toda a população de quinze a dezessete $\operatorname{anos}^{1}$ e elevar a taxa líquida de matrículas dessa etapa, tendo como uma das estratégias para alcançar tal fim: "pactuar entre União, estados, Distrito Federal e municípios [...] a implantação dos direitos e objetivos de aprendizagem e desenvolvimento que configurarão a Base Nacional Comum Curricular do Ensino Médio" (BRASIL, 2014, p. 53).

Lessard e Tardif (2004) observam que a prescrição de um programa nacional comum, centrado sobre os saberes de base, faz parte de um movimento de reestruturação escolar ao qual alguns países estão submetidos e que envolve outras medidas, como a descentralização de decisões, com incorporação da ideia de gestão em parceria. Considerando, então, essa tendência ao estabelecimento de uma BNCC e vendo-a como prática no Brasil, objetivamos refletir sobre o currículo dos jovens do Ensino Médio. Trata-se de um estudo de abordagem qualitativa, desenvolvido a partir de pesquisa bibliográfica e análise documental, cuja fonte central é a documentação oriunda do Ministério da Educação.

\section{Ensino Médio e desenvolvimento}

Nosella (2015, p. 123) afirma ser um equívoco considerar o Ensino Médio como uma fase intermediária entre o Ensino Fundamental e a universidade ou o mercado, pois na sua concepção é "a fase escolar estratégica do sistema escolar e do processo de democratização e modernização de uma nação". Como exemplo de sua importância, o autor cita a reforma empreendida na França, no contexto pós Segunda Guerra Mundial, no qual se priorizou essa etapa, valorizando sobremaneira os docentes que nela atuavam.

É possível observar a referência ao fato de o Ensino Médio ser parte do investimento em educação, de modo que Nosella (2015, p. 126) questiona: "Querem saber se um sistema escolar como um todo é de boa qualidade? Perguntem pelo ensino médio".

\footnotetext{
${ }^{1} \mathrm{O}$ que requer um elevado investimento (KUENZER, 2000).
} 
O retorno do investimento em educação em termos sociais "considera a relação entre custos e benefícios resultantes para a sociedade como um todo" (SHEEHAN, 1975, p. 35). Esse retorno social é evidente, porém, é possível calcular apenas os benefícios diretos e tangíveis, enquanto fatores importantes não são calculados devido a sua abrangência, por exemplo, maior estabilidade, coesão social, valores democráticos, entre outros. Talvez essa seja uma das razões das plataformas políticas não privilegiarem, apesar de aparecer em seus discursos, tal investimento. Nosella (2015, p. 126) identifica, ainda, que os gestores não têm uma concepção correta sobre a juventude alvo das políticas públicas propostas/implementadas: "adolescentes erroneamente considerados seres humanos despossuídos de sentido em si, meros projetos de futuros cidadãos adultos: alguns miniaturas de paletó e gravata, a maioria de macacão".

Sobre a maioria ser vista como "trabalhadores de macacão" em potencial, em referência aos jovens que não darão continuidade aos estudos e serão mão-de-obra imediata para o mercado, retomaremos a temática adiante, com a discussão da parte diversificada do currículo proposta com a BNCC, que possibilita a integração do ensino técnico ao Ensino Médio e os riscos de uma profissionalização precoce dos jovens pobres.

Por hora, apresentamos a reflexão de Dasgupta (2008, p. 33) sobre a importância de um país investir na continuidade dos estudos dos jovens, pois muitos economistas "[...] consideram a produção de novas ideias como o principal fator que impulsiona o progresso econômico”. O uso de novas ideias está mais presente nos países desenvolvidos, devido ao maior grau de instrução das pessoas. A ideia sustentada pelo autor é a de que os países que apresentam baixo índice de formação em nível superior não serão capazes de trabalhar com as novas tecnologias e também não conseguirão desenvolver novas ideias. No caso específico dos jovens brasileiros, concluir a Educação Básica tendo o Ensino Superior como caminho certo "é um 'luxo', há muito tempo garantido como direito apenas aos jovens dos estratos médios e altos da população" (MOURA; LIMA FILHO; SILVA, 2015, p. 1072), em outras palavras, é para "os que 
'nasceram competentes para estudar' e que, certamente, não são os pobres" (KUENZER, 2000, p. 26).

Pensando a educação no esteio econômico, Dasgupta (2008) afirma que destinar maior parte da renda à educação aumenta o PIB real, o que faz com que uma parte da renda seja destinada à produção de novas ideias, aumentando a produtividade e o acúmulo de capital fixo, de modo a se compor um círculo de prosperidade.

Na política educacional de 1990, o Ensino Médio não era a prioridade, pelo menos nos países subdesenvolvidos, ou polidamente chamados em desenvolvimento, pois a orientação dos organismos internacionais, novos interlocutores do governo, era dar prioridade ao Ensino Fundamental, em termos de universalização e programas de correção do fluxo idade/série, que ofereceria maiores possibilidades de retorno, sobretudo quanto ao alívio da pobreza (PERONI, 2003).

Assim, é possível observar que o destaque dado ao Ensino Médio é relativamente recente nas políticas públicas, ainda mantendo-se o velho problema do financiamento, pois o orçamento público das unidades federadas e da União não cobre adequadamente os custos básicos do sistema educacional, em que se pese a desvalorização docente e a falta de estrutura, vive-se o cenário de Emenda Constitucional no 95 de 15/12/2016, PEC do Teto dos gastos públicos, que Institui o Novo Regime Fiscal e congela os gastos em Saúde e Educação por vinte exercícios financeiros, isto é, vinte anos.

Especificamente com relação à reforma do Ensino Médio, foi aprovado pelo Parlamento brasileiro o empréstimo, junto ao Banco Internacional, para Reconstrução e Desenvolvimento (BIRD) para financiar a reforma educacional em algumas escolas de referência nos Estados. O Ministério da Educação (MEC) publicou a portaria n ${ }^{\circ} 727 / 17^{2}$ para instituir regime de colaboração de custeio nas escolas de referência, utilizando recursos do empréstimo contraído no BIRD. Nota-se que

\footnotetext{
${ }^{2}$ Institui o Programa de Fomento às Escolas de Ensino Médio em Tempo Integral - EMTI.
} 
os recursos são oriundos da simbiose entre educação e o mercado (banco), via empréstimo.

\section{Política educacional, currículo e a BNCC}

Promovendo uma análise de reforma do Ensino Médio do governo Fernando Henrique Cardoso (1995-2003), na qual o slogan era "o Ensino Médio agora é para a vida”, Kuenzer (2000) destaca a necessidade de desnudar o caráter parcial e interessado das ideologias para compreender os acertos e desacertos da proposta oficial de currículo para o Ensino Médio. Naquele momento, a autora observava que as diretrizes curriculares da reforma estavam em meio à realidade de "um imenso contingente de jovens que se diferenciam por condições de existência e perspectivas de futuro desiguais" (KUENZER, 2000, p.27). A conjuntura permanece a mesma, assim como a essência da proposta anterior coaduna com a atual. A reforma do Ensino Médio da década de 1990 estabelecia as competências a serem desenvolvidas e à formação básica sucederiam ênfases, escolhidas pelo aluno, que faria, ainda, escolhas entre disciplinas optativas para atender às suas preferências. Um currículo com metade das disciplinas obrigatórias e suas ênfases "reinventa a taylorização, agora pós-moderna, sob a justificativa da flexibilização", na perspectiva de Kuenzer (2000, p. 25). Dimensionando a problemática, a autora afirma que por outro lado, simplesmente estabelecer um modelo único não resolve a questão, "posto que submeter os desiguais a igual tratamento só faz aumentar a desigualdade" (ibid., p. 27).

Observa-se que na reforma aprovada no governo Michel Temer (2016-2018) ${ }^{3}$ há similaridade ideológica com a supracitada. Nesse esteio, ao falar em política educacional, faz-se necessário distinguir Estado e

\footnotetext{
${ }^{3}$ Michel Temer assume a presidência após um polêmico processo de impeachment (aceito em meio a possível articulação da oposição, encabeçada pelo candidato derrotado Aécio Neves, e interesses do então presidente da Câmara dos Deputados Eduardo Cunha) da presidente eleita Dilma Vana Rousseff, da qual ele foi vice no primeiro mandato (2011-2014) e no segundo (2015-2018), do momento de eleição até assumir a presidência da República.
} 
governo, dado que há papeis distintos quando se fala em garantir direitos sociais e quando se aborda a formulação e implantação de políticas públicas. Desse modo, entende-se o:

[...] Estado como o conjunto de instituições permanentes - como órgãos legislativos, tribunais, exército e outras que não formam um bloco monolítico necessariamente - que possibilitam a ação do governo; e Governo, como o conjunto de programas e projetos que parte da sociedade (políticos, técnicos, organismos da sociedade civil e outros) propõe para a sociedade como um todo, configurando-se a orientação política de um determinado governo que assume e desempenha as funções de Estado por um determinado período (HÖFLING, 2001, p. 31).

Dourado (2007) faz uma observação interessante quanto às políticas educacionais brasileiras, em sua constituição e trajetória histórica, afirmando que elas são marcadas pela lógica da descontinuidade, ou seja, constituem-se em políticas conjunturais de governo e não políticas de Estado, que envolvem um planejamento de longo prazo. Tal circunstância produz ações que não se articulam devidamente com os sistemas de ensino e isso impacta na estrutura curricular, por exemplo.

Em se tratando da atual BNCC aprovada para o Ensino Médio, o Ministério da Educação afirma que integra a política nacional da Educação Básica e contribuirá para o alinhamento de outras políticas e ações, em âmbito federal, estadual e municipal, na medida em que se constitui como referência nacional para a formulação dos currículos. A defesa é da necessidade de que "[...] sistemas, redes e escolas garantam um patamar comum de aprendizagens a todos os estudantes, tarefa para a qual a BNCC é instrumento fundamental" (BRASIL, 2017b, grifo nosso).

É relevante a preocupação de patamar mínimo de aprendizagens desde que atrelado ao padrão de qualidade ao qual a LDB faz referência: "garantia de padrão de qualidade" é encontrada no artigo $3^{\circ}$ (BRASIL, 1996), reafirmado no artigo 206 da CF/88 (BRASIL, 1988). O artigo $4^{\circ}$ da LDB, que se refere ao direito à educação e do dever de educar 
faz referência também ao padrão de qualidade. No inciso IX encontra-se a determinação de que sejam garantidos: "padrões mínimos de qualidade de ensino, definidos como a variedade e quantidade mínimas, por aluno, de insumos indispensáveis ao desenvolvimento do processo de ensino-aprendizagem". A questão da qualidade educacional é tratada ainda nos artigos 70 e 75 da LDB.

Lembramos que a questão da qualidade não pode ser separada do financiamento que a garanta. Ferretti e Silva (2017, p. 396) afirmam, ao examinarem as audiências públicas realizadas no Congresso Nacional sobre a MP n $\mathrm{n}^{0} 746$ e as alterações previstas para o currículo do Ensino Médio, que o setor privado teve um papel de destaque no percurso da MP em questão até a sua transformação em Lei, sobretudo na questão dos custos da oferta do Ensino Médio em tempo integral de sete horas diárias, questão que "esteve menos presente nas audiências públicas, provavelmente por haver consenso de que precisaria ampliar em muito o investimento público". Os autores transcrevem o posicionamento de Ricardo Henriquez, do Instituto Unibanco, para quem: "Não há nada que diga por que não termos cinco horas por dia. Isso é totalmente razoável, viável de ser financiado e administrado" (FERRETI; SILVA, 2017, p. 396).

Com a carga horária ampliada, dentro do que se considera possível de ser financiado pelo superintendente executivo do Instituto Unibanco, a proposta para o Ensino Médio se assenta na formação por competências. Assim, a BNCC é estruturada em dez competências gerais ${ }^{4}$ a

\footnotetext{
${ }^{4}$ 1. Valorizar e utilizar os conhecimentos historicamente construídos sobre o mundo físico, social, cultural e digital para entender e explicar a realidade, continuar aprendendo e colaborar para a construção de uma sociedade justa, democrática e inclusiva. 2. Exercitar a curiosidade intelectual e recorrer à abordagem própria das ciências, incluindo a investigação, a reflexão, a análise crítica, a imaginação e a criatividade, para investigar causas, elaborar e testar hipóteses, formular e resolver problemas e criar soluções (inclusive tecnológicas) com base nos conhecimentos das diferentes áreas. 3. Valorizar e fruir as diversas manifestações artísticas e culturais, das locais às mundiais, e também participar de práticas diversificadas da produção artístico-cultural. 4. Utilizar diferentes linguagens - verbal (oral ou visual-motora, como Libras, e escrita), corporal, visual, sonora e digital -, bem como conhecimentos das linguagens artística, matemática e científica, para se expressar e partilhar informações, experiências, ideias e sentimentos em diferentes
} 
serem desenvolvidas ao longo da Educação Básica e que devem orientar as decisões pedagógicas. O conceito de competência apresentado é: "mobilização de conhecimentos (conceitos e procedimentos), habilidades (práticas, cognitivas e socioemocionais), atitudes e valores para resolver demandas complexas da vida cotidiana, do pleno exercício da cidadania e do mundo do trabalho" (BRASIL, 2017b, p. 13).

No caso do Ensino Médio, a BNCC está organizada em quatro áreas de conhecimento, cada uma contando com as suas competências específicas, a serem desenvolvidas tanto no âmbito da BNCC como dos itinerários formativos das diferentes áreas: Linguagens e suas Tecnologias; Matemática e suas Tecnologias; Ciências da Natureza e suas Tecnologias; e, Ciências Humanas e Sociais Aplicadas. Essas áreas foram estabelecidas desde as Diretrizes Curriculares Nacionais do Ensino Médio (Parecer CNE/CEB no 15/1998). A cada uma das competências são relacionadas habilidades, que indicam as aprendizagens essenciais aos estudantes do Ensino Médio (BRASIL, 2017b).

contextos e produzir sentidos que levem ao entendimento mútuo. 5. Compreender, utilizar e criar tecnologias digitais de informação e comunicação de forma crítica, significativa, reflexiva e ética nas diversas práticas sociais (incluindo as escolares) para se comunicar, acessar e disseminar informações, produzir conhecimentos, resolver problemas e exercer protagonismo e autoria na vida pessoal e coletiva. 6 . Valorizar a diversidade de saberes e vivências culturais e apropriar-se de conhecimentos e experiências que Ihe possibilitem entender as relações próprias do mundo do trabalho e fazer escolhas alinhadas ao exercício da cidadania e ao seu projeto de vida, com liberdade, autonomia, consciência crítica e responsabilidade. 7. Argumentar com base em fatos, dados e informações confiáveis, para formular, negociar e defender ideias, pontos de vista e decisões comuns que respeitem e promovam os direitos humanos, a consciência socioambiental e o consumo responsável em âmbito local, regional e global, com posicionamento ético em relação ao cuidado de si mesmo, dos outros e do planeta. 8. Conhecer-se, apreciar-se e cuidar de sua saúde física e emocional, compreendendo-se na diversidade humana e reconhecendo suas emoções e as dos outros, com autocrítica e capacidade para lidar com elas. 9. Exercitar a empatia, o diálogo, a resolução de conflitos e a cooperação, fazendo-se respeitar e promovendo o respeito ao outro e aos direitos humanos, com acolhimento e valorização da diversidade de indivíduos e de grupos sociais, seus saberes, identidades, culturas e potencialidades, sem preconceitos de qualquer natureza. 10. Agir pessoal e coletivamente com autonomia, responsabilidade, flexibilidade, resiliência e determinação, tomando decisões com base em princípios éticos, democráticos, inclusivos, sustentáveis e solidários. 
Com relação aos itinerários formativos a serem oferecidos pelos sistemas de ensino "por meio da oferta de diferentes arranjos curriculares, conforme a relevância para o contexto local e a possibilidade dos sistemas de ensino" (BRASIL, 2017a) e pensando a ampliação de jornada determinada pela Lei n ${ }^{\circ}$ 13.415/2017 para o Ensino Médio, considera-se importante que o estatuto teórico mínimo seja elaborado, mas isso também vale "com referência às atividades formativas do contraturno" (NOSELLA, 2015, p. 140), que não parecem claras na política instituída.

No documento da BNCC se afirma o reconhecimento da juventude heterogênea, "entendida como diversa, dinâmica e participante ativa do processo de formação que deve garantir sua inserção autônoma e crítica no mundo" e o compromisso com a educação integral (BRASIL, 2017b). O que se questiona são as estratégias traçadas para atender ao público com tal característica. Essa juventude não homogênea está envolta no conceito de "aprender a aprender", em referência ao seu protagonismo e autonomia. Tal conceito é criticado por Almeida (2007, p. 120) para quem: “A autonomia não reside no 'aprender a aprender', mas na relação dialética que se deve estabelecer entre quem ensina e quem aprende". Ou seja, o autor considera que há uma mudança de discurso, a partir da Escola Nova, pois não se cabia mais a noção de igualdade dos alunos, enquanto estratégia para manutenção da escola burguesa, adota-se o discurso de que são diferentes entre si.

\section{Formação de professores}

O estabelecimento da BNCC impacta na formação de professores à medida que sintetiza os princípios, inclusive pedagógicos e políticos, sob os quais a prática em sala de aula deverá assentar-se. Tomamos aqui como foco os futuros professores, pois a preocupação é: os profissionais que colocarão a BNCC em prática terão em suas formações iniciais uma discussão apurada sobre no que consiste e como não vê-la enquanto meta de conteúdo a ser trabalhado? Aliado a essa preocupação é preciso considerar a necessidade de "[...] reforçar dispositivos e práticas de formação 
de professores baseadas numa investigação que tenha como problemática a acção docente e o trabalho escolar", como afirma Nóvoa (2011, p. 19). Logo, se a BNCC interfere na dinâmica do trabalho escolar, ela deve ser inserida nas discussões dos cursos de licenciatura.

Ao discutir a formação inicial de professores, deparamo-nos com o problema da desvalorização do ensino. Isso se deve, principalmente, em função do prestígio conferido à pesquisa em detrimento da prática em sala de aula. O problema que Pimentel (1993) evidenciou, ainda na década de 1990, nos resultados do estudo realizado com 14 docentes da Universidade de Campinas (Unicamp) de diferentes áreas (Exatas, Tecnológicas, Biológicas, Humanas e Artes $)^{5}$ se faz presente ainda hoje:

Com exceção dos professores 'representativos', cuja clareza de propósitos, traduzidos numa prática coerente e consistente com o paradigma que adotam, os outros, com maior ou menor complexidade e ambiguidade, fazem da graduação um ensino de segunda categoria. Não que seja esta a sua intenção ou que disso tenham consciência. Empenham-se na prática de ensino desse curso, certos de que fazem o melhor, mas não revelam o entusiasmo, a paixão, o mesmo envolvimento que demonstram ao falar na pós-graduação (PIMENTEL, 1993, p. 89, grifo nosso).

Alguns professores universitários se reconhecem como pesquisadores e esses que forjaram sua identidade na pós-graduação, ministram aulas na graduação porque são obrigados (exige-se dos professores universitários das instituições públicas que atuem por uma carga horária mínima nos cursos de graduação). Ainda que seja pela imposição, isso não muda a realidade de que são responsáveis, no caso dos professores que atuam nas licenciaturas, pela formação dos futuros professores e que devem colaborar para a reflexão a respeito do novo desenho de Ensino Médio que a BNCC apresenta. Trata-se de discutir o novo currículo desde a formação inicial dos professores, pois ao fim e ao cabo são eles que o operacionalizarão.

${ }^{5}$ Os sujeitos foram escolhidos a partir de informações coletadas junto aos concluintes de graduação em pesquisa anterior coordenada pelo Prof. Dr. Newton César Balzan. 
Fica claro que estabelecer alterações curriculares para o Ensino Médio sem que se faça um trabalho junto aos futuros professores pode fazer com que concepções inadequadas sobre a Base sejam levadas às escolas.

Tomamos como exemplo o caso do estado de São Paulo, no qual foi instituída uma nova proposta curricular, no ano de 2008, parte do Projeto São Paulo faz escola. A proposta era o de que as ações pedagógicas fossem desenvolvidas em torno da base curricular comum em todas as escolas da rede estadual. Então, um novo material chegou às escolas, os chamados Caderno do Professor e Caderno dos Alunos. Eram apostilas divididas em 4 volumes para o ano letivo. Ao analisar os Cadernos do Professor referentes à disciplina de Educação Física, Neira (2011, p. 26) conclui que: "[...] o professor é posicionado como mero transmissor de conhecimentos de pouca tradição, mediante uma abordagem superficial e sem qualquer espaço para a crítica ou para o reconhecimento dos seus saberes", isto é, há no material um caráter prescritivo 6 . Ou seja, o que era para ser uma base, em algumas escolas/diretorias de ensino, converteu-se em fim. Apesar da equipe do Projeto São Paulo faz escola afirmar, em um dos Cadernos (Ensino Médio, $3^{\mathrm{a}}$ série, volume 4), que: "O uso dos Cadernos em sala de aula foi um sucesso! [...]. O objetivo dos Cadernos sempre será apoiar os professores em suas práticas de sala de aula. Podemos dizer que esse objetivo foi alcançado" (SÃO PAULO, 2009, p. 6).

À medida que se propõem a refletir sobre as políticas para o Ensino Médio, focando nas Diretrizes Curriculares Nacionais (DCN) e na Base Nacional Comum Curricular (BNCC), Costa e Lopes (2018, p. 304) consideram que há uma restrição na política curricular, projetada por alguns para todos os outros e suposta/imposta como necessária à sociedade. Nesse sentido, os autores criticam "toda tentativa de orientação/controle de práticas de professores e alunos", ao passo que defendem outras

\footnotetext{
${ }^{6}$ Inclusive, algumas orientações pareceram bem prescritivas, como se observa no Caderno do Professor de Língua Portuguesa e Literatura, 3a série, volume 4: "Socialize as atividades propostas no Caderno do Aluno em Leitura e Análise de Texto" (SÃO PAULO, 2009, p.13).
} 
possibilidades de significação de currículo e contexto que estejam relacionadas a horizontes democráticos.

Os cursos de formação de professores devem propor o debate sobre a BNCC e seu papel em um país como o Brasil, populoso, multicultural, dentro da perspectiva da formação omnilateral do homem e da efetivação do direito de todos à educação.

É fundamental constatar que qualquer política educacional perpassa a figura do professor, embora não necessariamente ele seja sujeito convidado para a construção dessas políticas. Assim, os cursos de formação de professores têm um papel importante a desempenhar, de modo que aos que não são privilegiados pelo acesso a uma educação que forma para ocupar os postos de liderança na sociedade, "não interessa uma formação de professores que concorra para um trabalho alienado" (PEREIRA, 2010, p. 270).

\section{Considerações Finais}

O estabelecimento de aprendizagens mínimas, representado pela BNCC, é algo importante em um país com dimensões continentais como o Brasil, com diferentes sistemas de ensino, que devem articular-se em torno de objetivos comuns. No entanto, é imprescindível que a Base não se converta em um currículo mínimo a ser desenvolvido, o que cessaria seu potencial. Quanto aos itinerários formativos, cabe ressaltar a necessidade de maior clareza quanto às condições de sua oferta e financiamento. A subjetividade envolvida pode conduzir a uma formação técnica rasa e à falta de insumos, à má qualidade. Além dos arranjos a serem firmados com o setor privado, os quais devem ser mais bem explicitados nas políticas públicas voltadas à reconfiguração do Ensino Médio.

Alerta-se para o fato de a política educacional, historicamente, no Brasil, estar ligada a programas de governo, sobretudo quando se aborda currículo: revelador de dinâmicas de identidade e poder. De modo que, acredita-se que a essência para o novo Ensino Médio, enquanto política de Estado, deveria ser a de romper com a lógica de a etapa estar vinculada 
à continuidade nos estudos para jovens privilegiados. Mas é sabido que a política educacional, como parte de programa(s) de governo(s), está articulada a ideologias não propriamente comprometidas a dizimar ou melhorar as disparidades encontradas hoje em termos sociais e econômicos. Ainda assim, a defesa aqui é a de pensar modos que garantam uma educação de qualidade para os pobres, bem como seu acesso ao Ensino superior público.

Os cursos de formação de professores, licenciaturas de modo geral, têm a necessidade de estar articulados às novas concepções de currículo, estabelecidas pela BNCC, às reflexões sobre a prática em sala de aula e o objetivo de formação para o jovem do Ensino Médio. A reconfiguração da formação no ensino superior passa necessariamente pela valorização do ensino.

A educação é um caminho, talvez o único possível para o jovem pobre, porém, é necessário que se pense o currículo fora da manutenção da lógica de um sistema dual e que haja investimento público, não vinculado aos empréstimos bancários, dado que o dinheiro vem com receituário, para que se realizem as suas imensas possibilidades.

\section{Referências}

ALMEIDA, J. L. V. Aprender a aprender: uma sedução, com base na Escola Nova, para afirmar a escola burguesa. In: GRANVILLE, M. A. Teorias e práticas na formação de professores. Campinas: Papirus, 2007.

BRASIL. Constituição da República Federativa do Brasil (1988). Brasília: Senado Federal, 1988. Disponível em: <http://www.planalto.gov.br/ccivil_03/constituicao/constituicaocompilado.htm>. Acesso em: 29 de mai. 2018.

BRASIL. Lei de Diretrizes e Bases Da Educação Nacional. Lei no 9.394, de 20 de dezembro de 1996. Brasília, DF: Senado Federal, 1996. Disponível em: <http:// www.planalto.gov.br/ccivil_03/Leis/19394.htm>. Acesso em: 29 de mai. 2018. 
BRASIL. Plano Nacional de Educação 2014-2024 [recurso eletrônico]: Lei $n^{\circ}$ 13.005, de 25 de junho de 2014. Brasília: Câmara dos Deputados, Edições Câmara, 2014. Disponível em: <http://www.observatoriodopne.org.br/uploads/ reference/file/439/documento-referencia.pdf >. Acesso em: 30 de mai. 2018.

BRASIL. Lei no 13.415, de 16 de fevereiro de 2017. Brasília, DF: Senado Federal, 2017a. Disponível em: <http://www.planalto.gov.br/ccivil_03/_ato20152018/2017/lei/113415.htm>. Acesso em: 02 de jun. 2018.

BRASIL. Base Nacional Comum Curricular - Ensino Médio. Documento homologado pela Portaria n 1.570, publicada no D.O.U. de 21/12/2017, Seção 1, Pág. 146. Brasília, 21 de dezembro de 2017b.

COSTA, H. H. C.; LOPES, A. C. A Contextualização do conhecimento no Ensino Médio: tentativas de controle do outro. Educação \& Sociedade, Campinas, v. 39, n. 143, p. 301320, abr.-jun. 2018. Disponível em: <http://www.scielo.br/pdf/es/v39n143/16784626-es-es0101-73302018184558.pdf >. Acesso em: 11 de nov. 2018.

DASGUPTA, P. Economia. São Paulo: Ed. Ática, 2008.

DOURADO, L. F. Políticas e gestão da educação básica no Brasil: limites e perspectivas. Educação \& Sociedade, Campinas, v. 28, n. 100 (Especial), p. 921-946, out. 2007. Disponível em: <http://www.scielo.br/pdf/es/v28n100/a1428100. pdf >. Acesso em: 01 de jun. 2018.

FERRETTI, C. J; SILVA, M. R. da. Reforma do Ensino Médio do contexto da Medida Provisória n. 746/2016: Estado, currículo e disputas por hegemonia. Educação \& Sociedade, Campinas, v. 38, n. 139, p. 385-404, abr-jun. 2017. Disponível em: 〈http://www.redalyc.org/pdf/873/87351644008.pdf〉. Acesso em: 11 de nov. 2018.

HÖFLING, E. M. Estado e políticas (públicas) sociais. Cadernos Cedes, Campinas, v. 21, n. 55, p. 30-41, nov. 2001. Disponível em: <http://scielo.br/pdf/ccedes/ v21n55/5539>. Acesso em: 01 de jun. 2018. 
KUENZER, A. Z. O Ensino Médio agora é para a vida: entre o pretendido, o dito e o feito. Educação \& Sociedade, ano XXI, n. 70, abr. 2000. Disponível em: <http:// www.redalyc.org/pdf/873/87313696003.pdf>. Acesso em: 02 jun. 2018.

LESSARD, C.; TARDIF, M. Les transformations actuelles de l'enseignement: trois scenarios possibles dans l'évolution de la profession enseignante? In: LESSARD, C.; TARDIF, M. La profession d'enseignant aujourd'hui: évolutions, perspectives et enjeux internationaux. Québec: Université Laval, 2004.

MOURA, D. H.; LIMA FILHO, D. L.; SILVA, M. R. da. Politecnia e formação integrada: confrontos conceituais, projetos políticos e contradições históricas da educação brasileira. Revista Brasileira de Educação, v. 20, n. 63, p. 1057-1080, out./dez. 2015.

NEIRA, M. G. A proposta curricular do Estado de São Paulo na perspectiva dos saberes docentes. Rev. bras. Educ. Fís. Esporte, São Paulo, v. 25, suplemento n. 6, p. 23-27, nov. 2011.

NOSELLA, P. Ensino Médio unitário ou multiforme? Revista Brasileira de Educação, v. 20, n.60, p. 121-142, jan./mar. 2015.

NÓVOA, A. O Regresso dos Professores. Pinhais: Melo, 2011.

OLIVEIRA, D. A. Regulação das políticas educacionais na América Latina e suas consequências para os trabalhadores docentes. Educ. Soc., Campinas, v. 26, n. 92, p. 753-775, out. 2005.

PEREIRA, M. F. R. Formação de professores: debate e prática necessários a uma educação emancipada. Chapecó, SC: Argos, 2010.

PERONI, V. Política Educacional e papel do Estado: no Brasil dos anos 1990. São Paulo: Xamã, 2003.

PIMENTEL, M. G. O professor em construção. Campinas, SP: Papirus, 1993.

SÃO PAULO (Estado). Caderno do professor: Língua Portuguesa, Ensino Médio. Coord. geral Maria Inês Fini. São Paulo: Secretaria de Educação, 2009. 
SHEEHAN, J. A economia da educação. Rio de Janeiro: Ed. Zahar, 1975. (Traduzido da primeira edição, publicada em 1973 por George Allen \& UNIWIN LTD, de Londres, Inglaterra, na série "Studies in Economia nomics", organizada pelo Professor Charles Carter, da Universidade de Lancaster).

Recebido: 12/01/2018

Received: 01/12/2018

Aprovado: 28/11/2018 Approved: 11/28/2018 